\title{
Ohraa kasvavan turvepellon vuotuinen hiilidioksiditase
}

\author{
Annalea Lohila, Mika Aurela ja Tuomas Laurila \\ Ilmatieteen laitos, Ilmanlaadun tutkimus, Sahaajankatu 20 E, 00810 Helsinki.annalea.lohila@fmi.fi
}

\section{Johdanto \\ Turvepellot ja maatalouden hiilitase}

Suomen maatalouskäytössä olevasta peltoalasta noin $10 \%$ muodostuu nykyisin turvemaista, kun enimmillään niiden ala on kattanut jopa kolmanneksen viljeltävästä kokonaisalasta (Myllys, 1996). Aktiivisessa viljelykäytössä olevien turvepeltojen määrä vähenee edelleen jonkin verran, mutta silti niiden osuus kasvihuonekaasuina tunnettujen hiilidioksidin $\left(\mathrm{CO}_{2}\right)$ ja typpioksiduulin $\left(\mathrm{N}_{2} \mathrm{O}\right)$ lähteenä on merkittävä. Maatalouden aiheuttamista hiilidioksidipäästöistä Suomessa on jopa $65 \%$ arvioitu olevan peräisin orgaanisilta turvepelloilta (Pipatti, 2001). Maataloudesta aiheutuvat kasvihuonekaasupäästöt muodostavat arviolta $10 \%$ koko maan yhteenlasketuista päästöistä. Hiilidioksidin osuus maatalouden päästöistä on $\mathrm{CO}_{2}$-ekvivalentteina laskettuna noin neljännes, kun typpioksiduulin osuus on hieman yli puolet.

Kun suo ojitetaan maatalouskäyttöön, aiemmin hapettomana olleisiin turvekerroksiin pitkien aikojen kuluessa kertynyt humus ja muu hajoamaton kasvijäte pääsevät hapen kanssa tekemisiin. Tällöin mikrobitoiminnasta johtuva turpeen hajotus kiihtyy ja hiilidioksidipäästö kasvaa. Viljelykäytössä olevalla turvemaalla hiilidioksidi on osallisena erilaisissa prosesseissa. $\mathrm{CO}_{2}$ :a vapautuu ikivanhan turpeen hajotessa. Toisaalta peltokasvit sitovat hiilidioksidia yhteyttämisessä ja siirtävät osan sitomastaan hiilestä suoraan maahan, jossa tämä helpostihajoavassa muodossa esiintyvä hiili hapetetaan mikrobiprosesseissa nopeasti. Kasvit vapauttavat sitomaansa hiiltä suoraan myös kasvihengityksessä, johon osallistuvat niin juuret kuin maanpinnan yläpuolisetkin kasvinosat. Peltoekosysteemin hiilidioksiditase muodostuu näiden erisuuntaisten hiilidioksidivoiden summana. Hiilitaseen tuntemiseksi pitää lisäksi tietää sadonkorjuussa poistunut hiili, pohjavedessä poistuvan liukoisen orgaanisen aineksen (DOC) määrä sekä tuulieroosion aiheuttama mahdollinen hiilenhäviö.

Maatalousmaiden, ja erityisesti orgaanisten peltomaiden osalta kasvihuonekaasutaseiden laskentaan ja raportointiin tarvittavat päästökertoimet ovat olleet kansainvälisestikin puuttellisia ja epävarmoja perustuen harvoihin mittauksiin (Ympäristöministeriö, 2000). Turvemailla varsinaisia hiilidioksidin vaihdon mittauksia on tehty vain joitakin, ja nekin yhdellä menetelmällä, kammiomittauksin.

\section{Hiilidioksidin vaihdon mittausmenetelmistä}

Suoraa hiilidioksidin vaihtoa ilmakehän ja ekosysteemin välillä voidaan periaatteessa mitata joko kammiomenetelmillä tai mikrometeorologisilla menetelmillä. Kammiolla mitattaessa ekosysteemi suljetaan kammioon ja $\mathrm{CO}_{2}$-vaihdon suuruus määritetään mittaamalla $\mathrm{CO}_{2}$-pitoisuuden muutosta. Kammiomenetelmän etuja ovat mm. matalat hankintakustannukset, helppo siirreltävyys sekä vähäinen tai olematon sähköntarve. Erilaisten käsittelyjen ja toistojen sisällyttäminen kokeeseen on mahdollista ja helppoa, kun tarvittavat koealueet voivat olla pieniä, muutaman metrin kantiltaan olevia ruutuja. Myös alueellisen vaihtelun mittaaminen on helppoa.

Kammiomenetelmillä hankitut havaintoaikasarjat ovat usein vajavaisia, jolloin taseiden arvioinnissa joudutaan käyttämään enemmän mallitettuja kuin mitattuja tuloksia. Kammio toisaalta häiritsee mitattavaa ekosysteemiä. Kammion tiivistäminen maata vasten joko sellaisenaan tai erillisten kaulusten avulla aiheuttaa maan rakenteen rikkoutumisen, katkoo juuria, estää veden luonnollisen kulun maassa sekä saattaa muuttaa maan lämpötaloutta. Kammion sisäilman sekoittamiseen käytettyjen tuulettimien aiheuttamat ilmavirtaukset vaikuttavat maasta vapautuvan hiilidioksidin vuohon (Le Dantec ym., 1999). Tuulettimen käyttö aiheuttaa epäluonnollisia paineenvaihteluita maan huokosissa sekä maan yläpuolisessa ilmassa, ja irrottaa maasta ylimääräistä hiilidioksidia. Maan $\mathrm{CO}_{2}$-vuohon vaikuttavia paineenvaihteluita saattaa aiheutua myös kammiosta ilmaa imettäessä.

Mikrometeorologisilla menetelmillä, joista käytetyin on nk. kovarianssimenetelmä (eddy covariance method), ei häiritse tutkittavaa ekosysteemiä. Menetelmä perustuu ilmakehän turbulenttisten pyörteiden ja hiilidioksidin pitoisuuden nopeaan havainnointiin (5-10 krt/sek). $\mathrm{CO}_{2}$-vuo määritetään pystytuulen nopeuden sekä $\mathrm{CO}_{2}$-pitoisuuden kovarianssina tyypillisesti puolen tunnin keskiarvoina. Kovarianssimenetelmällä saatu vuo edustaa alueellista keskiarvoa nk. lähdealueelta, jolla tarkoitetaan kulloisestakin tuulensuunnasta ja -nopeudesta riippuvaa aluetta mittauspisteen ympärillä. Lähdealueen 
koko on tyypillisesti muutamia hehtaareja. Menetelmän heikkoutena voidaan pitää suuria hankintakustannuksia sekä sähkön tarvetta, ja lisäksi alueellisen vaihtelun selvittäminen lähdealueen sisällä on vaikeaa. Toisaalta menetelmällä voidaan ainakin teoriassa hankkia täydellinen mittausaikasarja. Laiteviat sekä epäedulliset meteorologiset olosuhteet, jollaisia ovat lähinnä tyynet tilanteet tai kova sade, aiheuttavat aukkoja ja siten paikkaustarvetta mittausaikasarjoihin. Aikasarjan paikkaaminen voidaan tehdä usealla tavalla. Yleinen, myös tässä käytetty, tapa on mallittaa $\mathrm{CO}_{2}$-vaihtoa semiempiiristen valo- ja lämpövastemallien avulla.

Ilmatieteen laitos on mitannut $\mathrm{CO}_{2}$ :n vaihtoa kovarianssimenetelmällä turvepellolla Jokioisissa vuoden 2000 helmikuusta saakka. Tässä kirjoituksessa pellon hiilidioksidin vuositasetta tarkastellaan ajanjaksolla lokakuulta 2000 lokakuulle 2001.

\section{Aineisto ja menetelmät}

Noin 16 ha kokoinen pelto kynnettiin lokakuun 2000 alussa, jota ennen alalla oli viljelty kevätviljaa. Seuraavana keväänä, 25. toukokuuta, alueelle kylvettiin nurmi suojaviljanaan Inari-ohra. Ohra puitiin sateisen syksyn vuoksi vasta 20 . syyskuuta, jonka jälkeen pelto jäi nurmelle. Orgaanisen hiilen määrä maaperässä on n. 25 paino-\%, humuksen määrä n. $45 \%$. Hiili-typpisuhde on n. 21.

$\mathrm{CO}_{2}$-vuon mittauslaitteisto koostui $\mathrm{CO}_{2} / \mathrm{H}_{2} \mathrm{O}$-analysaattorista sekä pysty- ja vaakasuuntaisen tuulennopeuden mittaamiseen käytetystä akustisesta anemometristä. Anemometri ja $\mathrm{CO}_{2}$-analysaattorille johtavan letkun suu sijaitsivat $3 \mathrm{~m}$ korkeudella. Kovarianssimittaussysteemi ja datankäsittelymenetelmät on kuvattu tarkemmin julkaisussa Aurela ym. (2001). $\mathrm{CO}_{2}$-vuomittauksen lisäksi alueella mitattiin tuulensuuntaa ja -nopeutta, ilman lämpötilaa ja kosteutta sekä maan lämpötilaa, kosteutta ja lämmönvuota. Myös säteilyn eri komponentteja mitattiin.

Kesällä 2001 ohran kasvua seurattiin mittaamalla ohran pituutta ja kasvuston lehtialaindeksiä (LAI) viikoittain. Kasvuston biomassamäärityksiä tehtiin 2 - 3 krt/kk.

\section{Tulokset ja tulosten tarkastelu}

\section{Hiilidioksidin vaihto vuoden eri aikoina}

Vuomittausaikasarjassa kasviton aika ja kasvukausi erottuvat selvästi toisistaan (Kuva 1). Pelto oli kynnöksellä lokakuun alusta toukokuun lopulle, jona aikana hiilidioksidin vuo maasta ilmaan oli tasaista ja pientä verrattuna kasvukauteen, jolloin sekä $\mathrm{CO}_{2}$ :n nettositominen (päiväarvot) että nettopäästö (yöarvot) olivat suuria.

Kasvittomalla ajalla kuukausittainen $\mathrm{CO}_{2}$-päästö kynnetystä turpeesta ilmaan oli $1-7 \mathrm{~g} \mathrm{~m}^{-2} \mathrm{~d}^{-1}$ (Kuva 2). Päästö oli pienimmillään maaliskuussa, jolloin myös maan lämpötila oli alimmillaan. Keski-

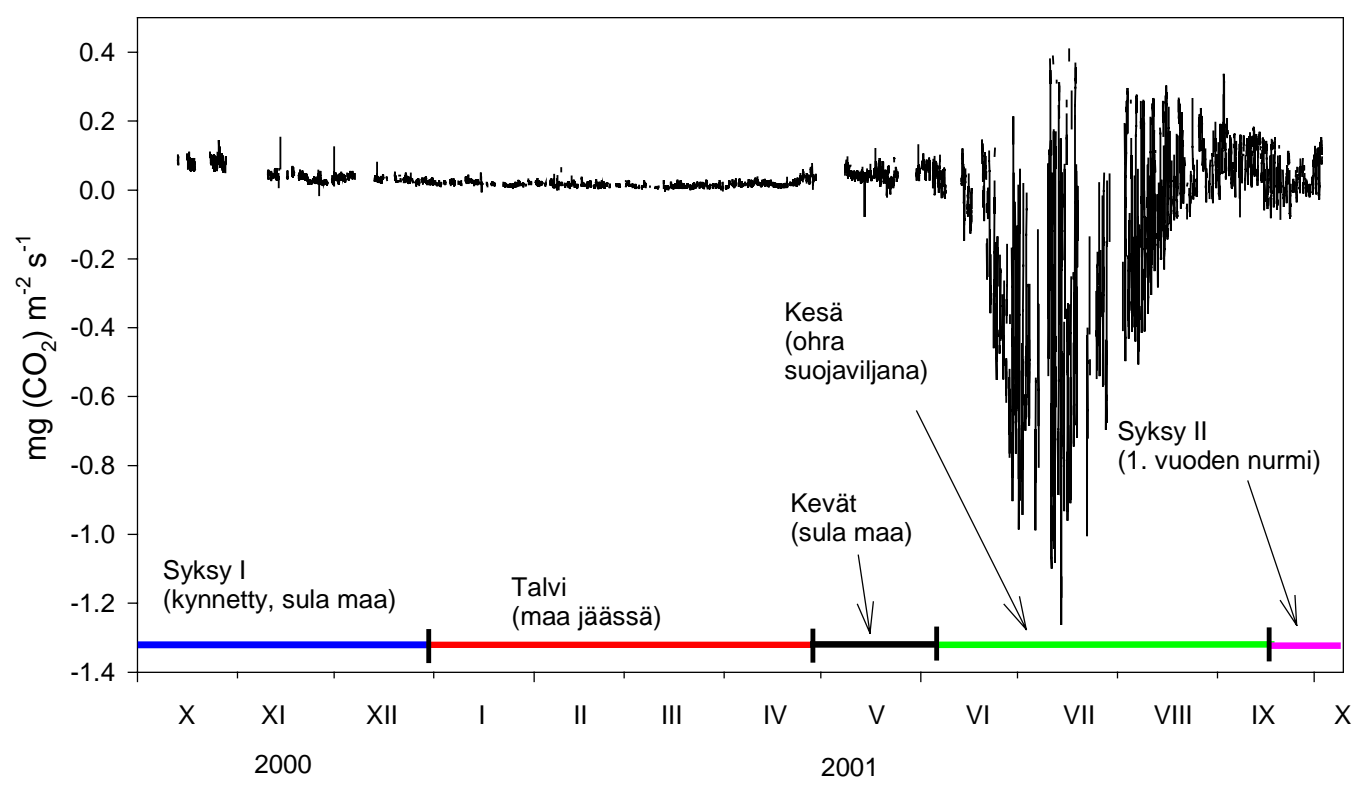

Kuva 1. Kovarianssimenetelmällä mitattu hiilidioksidin vaihto (puolen tunnin keskiarvoina) ajanjaksolla 12.10.2000 - 11.10.2001. Positiiviset arvot tarkoittavat $\mathrm{CO}_{2}$ :n nettovapautumista maaperästä ilmakehään, negatiiviset $\mathrm{CO}_{2}$ :n nettosidontaa. 
määräiset vuot olivat suurimpia lokakuussa kynnön jälkeen, jolloin maasta vapautui kaksi kertaa enemmän $\mathrm{CO}_{2}$ :a kuin toukokuussa, vaikka maan keskilämpötila oli sama. Ero johtui ilmeisesti siitä, että syksyllä maassa on vielä kesän jäljiltä runsaasti helposti hajoavaa kasvijätettä, joka on kevääseen mennessä pääosin hajonnut. Toisaalta myös muokkaus usein lisää hetkellisesti maan orgaanisen aineksen hajotusta ja kasvattaa $\mathrm{CO}_{2}$-vuota maasta. Vuonna 2000 loka-, marras- ja joulukuun keskilämpötilat olivat noin 4 astetta keskimääräistä lämpimämpiä ja maa jäätyi normaalia myöhemmin. Tuolloin mitatut vuot ovat todennäköisesti olleet suurempia kuin keskimääräisenä syksynä.

Toukokuun lopulla kylvetty ohra tuli oraalle kesäkuun alussa. Pian pensomisen alettua $\mathrm{CO}_{2}: n$ nettosidonta kasvoi voimakkaasti (Kuva 1). Ohran tähkälle tulo ajoittui heinäkuun alkupuolelle, jolloin mitattiin myös suurimmat hiilen nettosidonnan arvot, noin $-1.1 \mathrm{mg}\left(\mathrm{CO}_{2}\right) \mathrm{m}^{-2} \mathrm{~s}^{-1}$, ja suurimmat maa- ja kasvihengitystä kuvaavat yöarvot, noin $0.4 \mathrm{mg}\left(\mathrm{CO}_{2}\right) \mathrm{m}^{-2} \mathrm{~s}^{-1}$. Myös lehtialaindeksi saavutti maksiminsa (LAI=6) samoihin aikoihin. Tämän jälkeen $\mathrm{CO}_{2}$ :n oton huippuarvot pienenivät melko tasaisesti syksyä kohden ohranlehtien kellastuessa. Ohran alta puinnin jälkeen paljastunut nurmenalku osoitti fotosynteettistä aktiivisuutta syysjakson loppuun saakka. Maanpäällistä kasvibiomassaa oli syyskuun ensimmäiselle viikolle tultaessa kertynyt pellolle $980 \mathrm{~g} \mathrm{~m}^{-2}$, josta siemensadon osuus oli noin puolet.

\section{Turvepellon vuotuinen $\mathrm{CO}_{2}$-tase}

Ohraa kasvavasta turvepellosta vapautui vuoden aikana hiilidioksidia yhteensä noin $750 \mathrm{~g} \mathrm{~m}^{-2}$ (Taulukko 1). Jyväbiomassaan sitoutunut hiili, noin $200 \mathrm{~g} \mathrm{C} \mathrm{m}^{-2}$, ei sisälly tähän. Neljännes nettopäästöstä tapahtui talvella jäätyneen maan aikaan. Myös vuoden 2001 syysjaksolla pelto toimi hiilidioksidin lähteenä nurmesta huolimatta. $\mathrm{CO}_{2}$ :n päivittäistä nettosidontaa pellolla tapahtui pääasiassa kesäkuun viimeisen ja elokuun ensimmäisen viikon välisenä aikana. Kesäjakson aikana maa- ja kasvihengityksen seurauksena vapautui hiilidioksidia enemmän kuin minkään muun jakson aikana, yli $2000 \mathrm{~g} \mathrm{~m}^{-2}$, mutta ohra- ja nurmikasvusto sitoivat samaan aikaan

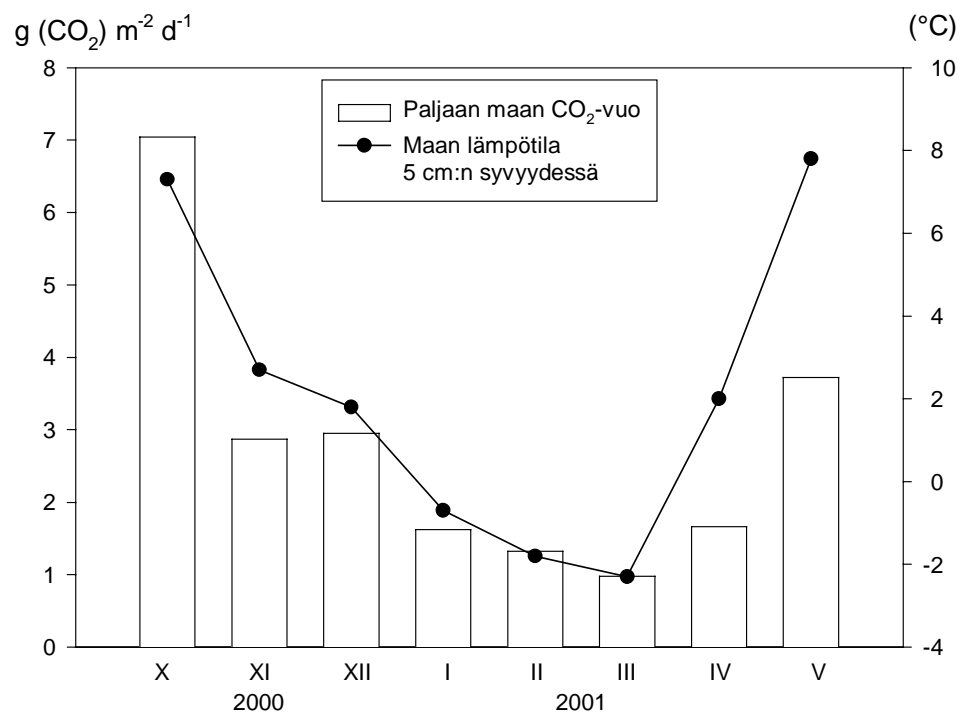

Kuva 2. $\mathrm{CO}_{2}$-vuon ja maan lämpötilan kuukausikeskiarvot kynnökseltä.

jotakuinkin yhtä paljon $\mathrm{CO}_{2}$ :a ja kesäjakson yli laskettu tase päätyi hyvin lähellä nollaa. Mallituksen avulla voidaan arvioida, että kesäjakson aikana pelkän maahengityksen seurauksena pellosta vapautui noin $1000 \mathrm{~g}\left(\mathrm{CO}_{2}\right) \mathrm{m}^{-2}$. Jos vuositase lasketaan käyttämällä kesäjakson kohdalla tätä maahengityksestä aiheutuvaa päästöä, tulee uudeksi vuositaseeksi noin $1700 \mathrm{~g}\left(\mathrm{CO}_{2}\right) \mathrm{m}^{-2}$. Teoriassa tämä tulos edustaa jonkinlaista karkeaa arviota paljaan, kasvittoman turvemaan $\mathrm{CO}_{2}$-vuositaseesta. Arvio on kuitenkin spekulatiivinen ja puhtaasti laskennallinen, perustuen pitkälti oletuksiin mallituksessa.

\begin{tabular}{|l|c|l|}
\hline Jakso & $\mathbf{g}\left(\mathbf{C O}_{\mathbf{2}}\right) \mathbf{~ m}^{-\mathbf{2}} \mathbf{j a k s o}$ & \\
\hline Syksy I $(12.10-25.12 .2000)$ & $319(4.4)$ & Pellon ilmiasu \\
\hline Talvi $(26.12 .2000-27.4 .2001)$ & $183(1.5)$ & kynnetty, maa sula \\
\hline Kevät $(27.4-31.5 .2001)$ & $115(3.4)$ & kynnetty, maa sula \\
\hline Kesä $(1.6-20.9 .2001)$ & $19(0.2)$ & ohraa (nurmi alla) \\
\hline Syksy II (20.9 - 11.10.2001) & $115(5.5)$ & 1 vuoden nurmi \\
\hline $12.10 .2000-11.10 .2001$ & $\begin{array}{c}751 \\
\left(\approx 7500 \mathrm{~kg} \mathrm{ha}^{-1} \mathrm{a}^{-1}\right)\end{array}$ & \\
\hline
\end{tabular}

Taulukko 1. Turvepellon vuotuinen hiilidioksiditaseen muodostuminen eri ajanjaksojen summana (positiivinen luku merkitsee $\mathrm{CO}_{2}$ :n nettopäästöä pellosta ilmaan). Sulkeissa keskimääräinen päiväpäästö kyseiseltä jaksolta.

Tasearviomme $750 \mathrm{~g}\left(\mathrm{CO}_{2}\right) \mathrm{m}^{-2}$ on hyvin lähellä Armentano \& Mengesin (1986) turpeen vajoamisnopeuteen perustuvaa vuosipäästöarviota boreaalisella vyöhykkeellä sijaitsevalle viljellylle turvemaalle, $800 \mathrm{~g}\left(\mathrm{CO}_{2}\right) \mathrm{m}^{-2}$. Maljanen ym. (2001) arvioivat kammiomenetelmään perustuen ohraa kasvavan tur- 
vepellon vuositaseeksi $1500 \mathrm{~g}\left(\mathrm{CO}_{2}\right) \mathrm{m}^{-2}$. Ero johtuu osittain turvepeltojen toisistaan poikkeavista ominaisuuksista, kuten turpeen iästä ja laadusta. Osa erosta saattaa selittyä mittausmenetelmien välisillä eroilla. Koizumi ym. (1999) mittasivat pelkkää maahengitystä kammiomenetelmällä samalla pellolla, jossa tämä tutkimus on tehty. $\mathrm{He}$ arvioivat kasvittoman turvemaan $\mathrm{CO}_{2}$-päästöksi 5 kesäkuukauden ajalta lähes $1700 \mathrm{~g} \mathrm{~m}^{-2}$. Tämä on yhtä paljon kuin oma arviomme kasvittoman pellon $\mathrm{CO}_{2^{-}}$ päästöstä koko vuoden ajalta.

\section{Johtopäätökset}

Maatalouskäytössä olevan turvepellon hiilidioksiditase on arvioitu ensimmäisen kerran kovarianssimenetelmällä tehtyihin mittauksiin perustuen. Vuositase, $7500 \mathrm{~kg} \mathrm{ha}^{-1}$, on pienempi kuin aiemmat, lähinnä kammiomenetelmällä saadut arviot turvepelloilta vapautuvan hiilidioksidin määristä. Tulos vahvistaa kuitenkin käsitystä viljelykäytössä olevista turvepelloista merkittävinä hiilidioksidin lähteinä. Tiedolla on käyttöä kansainvälisestikin päästökerrointen tarkentamisen kannalta, sillä ojitettujen turvemaiden hiilidioksidipäästöjä ja -taseita on tutkittu vain vähän.

Turvepeltojen suuren kokonaispinta-alan vuoksi niiden rooli kansallisessa maatalouden kasvihuonekaasutaseessa on tärkeä. Jatkossa tulisikin selvittää, voidaanko viljelymenetelmiä muuttamalla estää hiilidioksidin vuotuinen nettovapautuminen turvemailta, tai voidaanko maatalouskäytössä oleva turvemaa muuttaa jopa hiilidioksidin nieluksi. Jos tällaisia keinoja ei löydy, on Kioto-prosessia silmälläpitäen tarpeen miettiä, pitäisikö näiden alueiden maankäyttöä pyrkiä ohjaamaan vähäpäästöisempään suuntaan. Päätöksenteossa on kuitenkin lisäksi huomioitava, että turvemaat ovat myös potentiaalisia dityppioksidin ja metaanin lähteitä, eikä mitään päätöksiä voida tehdä tuntematta näiden kaasujen syntymekanismeja, dynamiikkaa sekä vaikutusta kokonaiskasvihuonekaasutaseeseen turvemailla.

Armentano, T.V. \& Menges, E.S. 1986. Patterns of change in the carbon balance of organic soil-wetlands of the temperate zone. J. Ecol. 74, 755-774.

Aurela, M., Laurila, T. \& Tuovinen, J-P. 2001. Seasonal $\mathrm{CO}_{2}$ balances of a subarctic mire. J. Geophys. Res. 106, 1623-1637.

Koizumi, H., Kontturi, M., Mariko., S., Nakadai., T., Bekku., Y. \& Mela, T. 1999. Soil respiration in three soil types in agricultural ecosystems in Finland. Acta Agriculturae Scandinavica, B: Soil and Plant Science, 49, 65-74.

LeDantec, V., Epron D., \& Dufrene E. 1999. Soil $\mathrm{CO}_{2}$ efflux in a beech forest: comparison of two closed dynamic systems. Plant and Soil 214, 125-132.

Maljanen, M., Martikainen, P.J., Walden, J. \& Silvola, J. 2001. $\mathrm{CO}_{2}$ exchange in an organic field growing barley or grass in eastern Finland. Global Change Biol. 7, 679-692.

Myllys M., 1996. Agriculture on peatlands. In: Vasander, H. (ed.): Peatlands in Finland. Finnish Peatland Society, Helsinki, p. 64-71.

Pipatti, R. 2001. Greenhouse gas emissions and removals in Finland. VTT Res. notes 2094, Espoo.

Ympäristöministeriö, 2000. Suomen kasvihuonekaasupäästöjen laskennan kehittäminen. Kaasutyöryhmän työraportti. Ympäristöministeriön monistesarja, 59. 